DOI: 10.23860/JMLE-2019-11-2-4

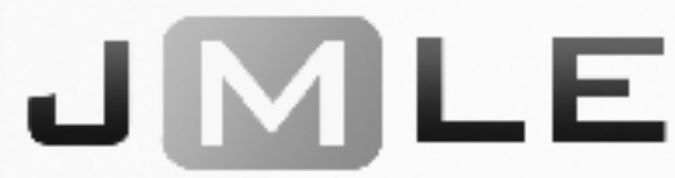

The National Association for Media Literacy Education's Journal of Media Literacy Education 11 (2), 56 - 78

\title{
Story Sharing in a Digital Space to Counter Othering and Foster Belonging and Curiosity among College Students
}

\author{
Gina Baleria \\ Sonoma State University, USA
}

\begin{abstract}
The purpose of this exploratory qualitative study was to discover how a single, relational intervention in a digital space focused on civil, respectful conversation across difference might influence digital media literacy (DML) among college students, with the goal of increasing college students' sense of belonging and level of curiosity. The researcher used a phenomenological approach, exploring and describing the lived experiences of students who participated in a microengagement with an other through interviews (Creswell, 2014). This study investigated the main question: (a) How does a semi-structured, relational micro-intervention focused on civil, respectful conversation across difference influence college students' sense of belonging and level of curiosity? This research was guided by the Framework for Individual Diversity Development (Chavez, GuidoDiBrito, \& Mallory, 2003), which provided a theoretical model for the process of moving from lack of awareness and othering to awareness and acceptance. Findings that emerged involved students' recognition that a semi-structured micro-intervention with an other in a digital space enlightened them to the value of story sharing to navigate differences, find commonality, and establish smallscale relationships. These key findings indicate that the time and structure involved in a relational micro-interventions across difference in a digital space can influence DML, sense of belonging, and level of curiosity.
\end{abstract}

Keywords: digital media literacy, micro-intervention, semi-structured, counter-story, belonging, curiosity, relationship, engagement, persistence

Digital and social media are now ubiquitous for college students (Junco \& Cole-Avent, 2008; Moeller, 2010; Roberts, Yaya, \& Manolis, 2014), who see their phones and tablets as portals to real spaces in which they engage and carry out various types of relationships, often as an extension of campus, class, friendship, and family. This is particularly true at community colleges (CC), where students may be attending remotely or commuting. However, research has indicated that students have not been taught the digital media literacy (DML) skills to navigate these spaces, assess and decipher messages (Kahne \& Bowyer, 2016; Kim \& Yang, 2016; McGrew, Breakstone, Ortega, Smith, \& Wineburg, 2018; Simsek \& Simsek, 2013); and communicate and engage in ways that are productive, respectful, and empathetic (Park, Kim, \& Na, 2014). 
For the purposes of this research, DML is defined as a set of skills that prepares and empowers students to assess and critique information online, challenge and change messages they hear, and engage more respectfully with others (Martens \& Hobbs, 2015), critical building blocks of engagement and belonging. A lack of DML can lead to students othering or being othered in digital spaces. Othering is when one develops an us-versus-them mentality and then excludes, often via marginalization of (Young, 1990) or lack of curiosity about those considered them (Johnson et al., 2004). When students feel othered or marginalized, their feelings of belonging decrease-negatively impacting campus climate, engagement, and ultimately persistence, retention, and success (Hausmann, Schofield, \& Woods, 2007; Masika \& Jones, 2015; O’Keeffe, 2013). Ultimately, othering can impact societal discourse and democracy.

This study explored how a semi-structured micro-intervention involving engagement across one or more salient social and/or political differences in a digital space influenced belonging and curiosity among students at a Northern California CC. Belonging and curiosity are two factors that influence desire and openness to engage (Buote et al., 2007; Hausmann et al., 2007; Hulme, Green, \& Ladd, 2013; Locks, Hurtado, Bowman, \& Oseguera, 2008; Masika \& Jones, 2015; O'Keeffe, 2013), making them foundational elements for the teaching of DML. This study investigated the main question: (a) How does a semi-structured, relational microintervention focused on civil, respectful conversation across difference in a digital space influence college students' sense of belonging and level of curiosity?

This study was conducted using CC students, because of the challenges involved in student persistence, retention, and success at CCs. Less than half of all California CC students (48\%) transfer or complete a certificate or Associate's degree within six years of initial enrollment. For students from marginalized backgrounds, the numbers are even more concerning: $40.8 \%$ after six years (California Community Colleges Key Facts, 2016). This study focused on both historically marginalized and historically privileged students, because all groups must learn how to communicate and listen to each other to build understanding and create a climate in which everyone feels a sense of belonging, curiosity about the other, and safe when engaging in a relationship across difference. DML skills are integral to this process. As Freire said, literacy is not just about reading the word, but also the world (Freire \& Macedo, 1987). Today, reading the world requires understanding how to "read" cues and content in digital spaces, as well as across cultures and difference (Betancourt, Green, \& Carillo, 2003).

This research has taken on particular significance in the wake of the 2016 presidential election and the growing consensus that Americans perceive the nation as divided (Enter the Electome 2016; Suh, 2014). Strategies and tools to bridge divides, combat othering, and teach people how to engage and build relationships with others who are different are critical to combating this problem (DiMaggio \& Garip, 2012; Hurtado \& Ponjuan, 2005; Locks et al., 2008; Mendoza-Denton \& Page-Gould, 2008). College students are in a position to influence the direction of their communities and society. Therefore, it is imperative that we provide them opportunities to develop the DML skills necessary to navigate digital and social 
media spaces and engage and build relationships with those who are different from them (Hall, Cabrera, \& Milem, 2010).

\section{THEORETICAL FRAMEWORK}

Research indicates that a conscious approach to opposing and reducing otherness by fostering connection and relationship building may be effective (Bennett, 1993; Chavez, Guido-DiBrito, \& Mallory, 2003). The theoretical framework that guided this study frames the process for moving from othering and lack of curiosity to awareness and acceptance (Chavez et al., 2003). The process it describes applies to students' experiences as they engage in a semi-structured relational micro-intervention across difference in a digital space. Chavez et al. (2003) noted that "consciously searching for at least one commonality may be the first bridge toward valuing and validating others" (p. 466). This suggests that a relational semi-structured micro-intervention might be effective in helping students move along the spectrum depicted in Figure 1 by gaining exposure to those who are different from them. As Chavez et al. (2003) noted, "Once individuals accept the possibility of relativism, it is difficult - if not impossible - to retreat to dualism" (p. 461). Given that this process can be fraught with challenges, including fear of letting go of a previous mindset, guilt over betraying people who taught previous beliefs and practices, and uncertainty about how to engage with people who are different, it is critical that community college leaders provide guidance and structure to students in such a process.

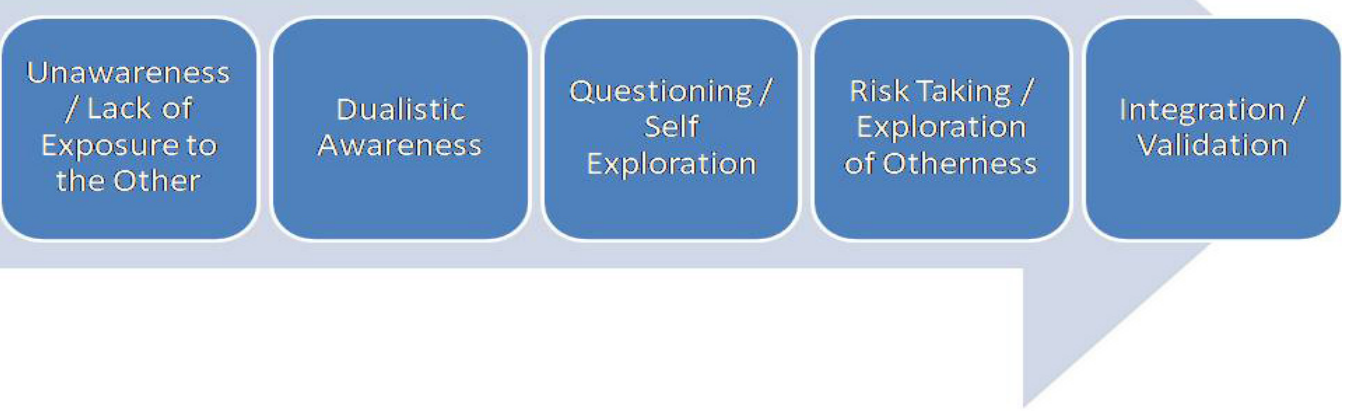

Figure 1. Theoretical framework of moving from othering to acceptance. Adapted from "Learning to Value the Other: A Framework of Individual Diversity Development," by A. F. Chavez, F. Guido-DiBrito, and S. L. Mallory, 2003, Journal of College Student Development, 44(4), p. 459. Copyright 2003 by American College Personnel Association-College Student Educators Intl.

This framework enabled the assessment of significance and meaning in student experiences and responses, and it provided clues for whether an engagement across difference may influence student curiosity and sense of 
belonging through the experience of engaging in a positive small-scale relationship across difference.

\section{LITERATURE REVIEW}

Given the growing body of research on the ubiquitous nature of digital media to students' lives (Junco \& Cole-Avent, 2008; Moeller, 2010; Roberts et al., 2014), as well as student's dependence on digital media for engagement (Kim, Wang, \& Oh, 2016; Moeller, 2010), it is important to explore how students are engaging and pursue the fostering of belonging, curiosity, and DML. This literature review examines the research on DML and engagement; how micro-interventions can influence belonging, curiosity, and attainment; and how relationships intersect with engagement, belonging, and curiosity.

\section{Digital Media Literacy}

Several studies establish the ubiquitous nature of digital media to the lives of today's college students and students' dependence on digital media tools for engagement (Junco \& Cole-Avent, 2008; Moeller, 2010; Roberts et al., 2014). Students consider mobile devices as critical to maintaining relationships and conducting everyday tasks (Kim et al., 2016) and consider a day without their mobile device as a day without access to relationships with friends and family (Moeller, 2010). Students who attend commuter schools or take online courses rely on digital spaces to connect with professors and peers, complete assignments, and stay current on college activities and information. Several studies suggest that digital media use can facilitate engagement, rather than inhibit it (Enjolras, SteenJohnsen, \& Wollebaek, 2013; Gil de Zuniga, 2012; Kim et al., 2016). DML education has been correlated with increased political engagement online and a greater exposure to diverse perspectives (Kahne, Lee, \& Feezell, 2012; Kim \& Yang, 2016; Mihailidis \& Thevenin, 2013). Engagement in online communities has been linked to student attainment (Fagioli, Rios-Aguilar, \& Deil-Amen, 2015), and research has shown that social media may allow students to forge connections with more diverse others and develop stronger relationships than they would in a traditional class setting (Junco \& Cole-Avent, 2008). Digital media may also allow students who don't feel comfortable speaking in class to engage more meaningfully in course discussions (Junco \& Cole-Avent, 2008).

However, though today's college students are considered digital natives who have grown up engaging with digital media, many do not have well developed DML skills, including networked individualism, the ability to develop and maintain relationships in digital spaces (Park et al., 2014), a necessary skill set for a vibrant participatory democracy (Simsek \& Simsek, 2013). Research finds that guidance is necessary to help students hone their DML skills (Hargittai, Fullerton, MenchenTrevino, \& Thomas, 2010; Kahne \& Bowyer, 2016; McGrew et al., 2018).

In addition, many students who engage online may find themselves marginalized or marginalizing others through cyber-bullying and gossip (Smith, Mahdavi, Carvalho, Fisher, Russell, \& Tippett, 2008). Instead of improving engagement and relationships, online communication may silence dissenting voices, often among people who are marginalized and othered (Smith et al., 2008), 
further excluding those outside the mainstream. Research also finds that people are not engaging meaningfully with those outside their social or political circle- the other - on issues impacting their community or affecting democracy (Kahne \& Bowyer, 2016; Enter the Electome, 2016). The deliberate and conscious teaching of DML skills can help address this challenge.

\section{Micro Interventions}

Micro-interventions are an emerging area of research with the promise that small, scalable interventions designed to address significant problems can result in positive outcomes (Walton \& Cohen, 2011; Walton, Logel, Peach, Spencer, \& Zanna, 2015). Longitudinal experimental research studies on Black and female college students show that micro-interventions can close opportunity gaps, improve health outcomes, and increase belonging (Walton \& Cohen, 2011; Walton et al., 2015). To test the influence of a small intervention on belonging, health, and academic outcomes of Black $(\mathrm{N}=49)$ and White $(\mathrm{N}=43)$ college students, Walton and Cohen (2011) conducted a quantitative, longitudinal, experimental study involving a brief intervention at the beginning of freshman year defining social adversity as normal and short-lived, and a measurement three years later. Researchers found that grade point averages (GPA) of all students in the treatment group rose (Black, $\mathrm{p}=.0007$; White, $\mathrm{p}=.014$ ), and the gap between White and Black students closed $79 \%$. This did not occur in the control group. Black students in the treatment group also reported fewer doctor visits $(28 \%)$ than those in the control group (60\%), eliminating the race gap in self-reported health. Positive outcomes were also seen in a randomized, controlled, longitudinal study using a belonging micro-intervention with female engineering students in a male-dominated major at an elite university (Walton et al., 2015). The GPAs of female students (N=92) in the experimental group increased, erasing the gender gap with male classmates $(\mathrm{N}=136)$. Implications are that small interventions can have large and lasting effects on the success and well-being of historically marginalized student groups. Microintervention research has also shown promise in stress reduction (Smyth \& Heron, 2016), coping mechanisms for post-traumatic stress disorder (Itzhaky \& Dekel, 2005), parenting and childhood obesity (Ayala et al., 2010), mobile app use (Smyth \& Heron, 2016), psychological capital (Luthans, Luthans, \& Avey, 2014), transportation (Caminha, Furtado, Pinheiro, \& Silva, 2016), and organizational behavior (Nelson \& Cooper, 2007). Researchers note that micro-interventions are scalable, easy to implement, and effectively paired with semi-structured approaches (Itzhaky \& Dekel, 2005; Smyth \& Heron, 2016).

\section{Relationships}

Engagement, belonging, and curiosity are foundational elements of relationship building (Buote et al., 2007; Shook \& Clay, 2012; Smith \& Schonfeld, 2000). However, previous research has generally framed relationships as sustained interactions among individuals (Hammer, 1983). Research is well established on the importance of sustained relationships to social well being (O'Neal, Mancini, \& Degraff, 2016), health outcomes (Lieberman, 2013), and community health (Bruhn, 2004). Research is lacking as to the influence and significance of relationships that 
may not sustain. These small-scale relationships are foundational to the fabric of a community, including online communities, and may involve one small or short interaction with an individual, such as a micro-aggression (Pierce, 1970) or microinclusion (Aguilar, Walton, \& Weiman, 2014), small interactions that can have large negative or positive impacts. It is important to explore the impact of smallscale relationships, because they are ubiquitous to people's everyday lives and can reverberate throughout society.

Research exploring the cultivation of small-scale relationships across difference in a digital space can fill gaps in the literature. Small-scale relationships involving story sharing-narrative and counter-narrative (Delgado, 1989; Solórzano \& Yosso, 2002)—can influence belonging, curiosity, and DML by empowering marginalized students and enlightening the privileged (Delgado, 1989; Ladson-Billings \& Tate, 1995). This study fills gaps in the literature by focusing on a relational micro-intervention across difference involving small-scale relationship building through story sharing.

\section{Belonging}

Research has established that cultivating belonging can lead to increased student engagement and positively impact persistence, retention, and success (Hausmann et al., 2007; Masika \& Jones, 2015; O'Keeffe, 2013). This is especially true for non-traditional or marginalized students (Hausmann et al., 2007). Here, belonging is defined as a student feeling a valued, included, accepted member of the campus community (Hausmann et al., 2007; Masika \& Jones, 2015). Several studies have illuminated the importance of campus connections and relationships on student sense of belonging and level of campus engagement (Bonet \& Walters, 2016; Masika \& Jones, 2015), reinforcing how critical it is to make belonging a structural part of any approach to student integration on campus.

\section{Curiosity}

Another factor shown to foster engagement, relationship building, and student success is curiosity, defined as "a willingness to explore the unknown, embrace novelty, and accept uncertainty" (Mather \& Hulme, 2013). Several studies establish curiosity's role in student engagement (Buote et al., 2007; Hulme et al., 2013; Locks et al., 2008) and success (Shook \& Clay, 2012). Given that curiosity can be developed through uncertainty and unpredictability (Silvia, 2008), and that curious students perceive difficulties as opportunities (Mather \& Hulme, 2013), research that places students into a controlled situation involving uncertainty and unpredictability and defines the situation as an opportunity may help foster curiosity, which can in turn help students engage and build relationships across difference.

\section{Engagement with Diverse Others}

An area of engagement with particular influence on belonging, curiosity, and persistence is engagement with diverse others. Several studies establish that students who build relationships with those different from them-or otherincrease sense of belonging, curiosity, and intent to persist (Buote et al., 2007; 
Hausmann et al., 2007; Shook \& Clay, 2012). Positive outcomes are seen for both marginalized and privileged students (Buote et al., 2007; Hausmann et al., 2007). Interaction with diverse others early in college can also shatter stereotypes, decrease prejudice, increase understanding, strengthen student satisfaction, and improve cognitive learning outcomes (Smith \& Schonfeld, 2000). Research indicates that such engagement is a learned behavior (Hall et al., 2010). Therefore, interventions, such as a relational micro-intervention across difference, may be best implemented by community college administrators, faculty, or staff, who can provide students with support, guidance and instruction.

\section{METHODOLOGY}

This exploratory, phenomenological qualitative study, focused on learning what participating students had to say about their experiences engaging in a single, relational, semi-structured micro-intervention across difference in a digital space. Careful attention was given to what students reported thinking, the way they described their experience, how they applied meaning to it, and the potential implications for belonging and curiosity. In keeping with the principles of phenomenological qualitative research, in which the intent is to elucidate a particular phenomenon and not to generalize (Creswell, 2014), a targeted purposive sample was used (Creswell, 2014). The intent was to explore an intervention focused on civility and respectful conversation across difference that had not been researched. Strauss and Corbin's (1998) assertion that qualitative research methods can be effectively employed to improve understanding of a practice about which not much is known is applicable in this case.

\section{Participation and Sampling}

The 16 students who participated in this study represented a sub-set of 52 students from a Northern California community college who participated in a larger study on engagement across difference. Of the 52, a random sample of 34 engaged in a digital micro-intervention across difference with other students from a twoyear college in the Appalachian Region, and 18 served as a control group for the larger study. Of the 34 who engaged in the micro-intervention, 16 were selected to participate in this exploratory study. Purposive sampling was used because the goal of this study was to come to a deep understanding of the groups' experiences, and a random sample was not appropriate, desirable, nor feasible from a methodological or practical perspective (Miles, Huberman, \& Saldaña, 2014). This purposive sample may provide insights into larger student populations and avenues for further study.

The 16 students who participated in this study represent a diverse crosssection of the student population on this campus; $40 \%$ identified as non-White, in alignment with college and area demographics. However, many students who identified as White were marginalized and othered for sexual identity and orientation, first gen status, and socio-economic status (SES). Many held jobs and attended school only part-time, lived at home to save money, and passed on opportunities to begin college at four-year institutions because of cost concerns. 
See Table 1 for an overview of study participant demographics. Each student has been given a pseudonym to protect anonymity.

Table 1.

Study Participant Demographics

\begin{tabular}{|c|c|c|c|c|}
\hline $\begin{array}{l}\text { Student } \\
\text { (pseudonym) }\end{array}$ & Ethnicity & Generation & Year & Orientation \\
\hline Angela & Mixed & $1^{\text {st }}$ Gen & $\mathrm{Jr}$ & Bi/Pan/Poly \\
\hline Angelica & Latina & 1st Gen w/ single parent & Soph & Straight \\
\hline Bella & Mixed & 1st Gen & Soph & Straight \\
\hline Ben & Mixed & Non- $1^{\text {st }}$ Gen & Frosh & Straight \\
\hline Kathy & White & 1st Gen & $\mathrm{Jr}$ & Straight \\
\hline Kristina & White & 1st Gen & $\mathrm{Sr}$ & Straight \\
\hline Maria & Mixed & 1st Gen w/ single parent & Frosh & Bi/Pan/Poly \\
\hline May & Asian & Non- $1^{\text {st }}$ Gen & Soph & Straight \\
\hline Michael & White & Non- $1^{\text {st }}$ Gen & Frosh & Gay/Lesbian \\
\hline Omar & Mixed & 1st Gen & Soph & Straight \\
\hline Rico & Latino & 1st Gen & Frosh & Gay/Lesbian \\
\hline Rochelle & White & Non- $1^{\text {st }}$ Gen & Soph & Straight \\
\hline Sam & White & 1st Gen & Soph & Straight \\
\hline Sarah & White & Non- $1^{\text {st }}$ Gen & Soph & Straight \\
\hline Shawntel & Black & 1st Gen w/ single parent & $\mathrm{Jr}$ & Straight \\
\hline Tommy & White & 1st Gen & Soph & Straight \\
\hline
\end{tabular}

\section{Data Collection}

Data were collected from qualitative interviews with 16 students who engaged in the semi-structured micro-intervention with someone considered their other. Interviews were conducted in June and July 2017, after the conclusion of the spring 2017 semester and after grades were submitted to ensure that students did not feel pressure to participate or respond in a certain way.

Micro-interventions took place on Mismatch.org, an online portal developed by the researcher in collaboration with the nonprofit organizations Civity and AllSides for Schools. The goal was to match people with an other and guide them through a 45-60 minute semi-structured video engagement across a socially salient difference. Otherness was determined based on factors gleaned from a preengagement survey completed as part of the matching process, including SES, ethnicity and race, age, political leaning, gender, and sexual orientation. Creswell (2014) explained that qualitative and quantitative research often lay on a continuum and sometimes involve the use of opposing data collection methods for various reasons, including for use as screening tools.

\section{Data Analysis}

All interviews were audio recorded and transcribed verbatim. The first round of coding involved a comprehensive, systematic content analysis of each 
interview, utilizing emergent coding, including in vivo (Charmaz, 2002), descriptive, emotion and process (Charmaz, 2002; Strauss \& Corbin, 1998). The second round of coding utilized sub-coding, pattern coding, and structural coding (Miles et al., 2014). This helped in the identification of larger themes that shed light on the significance of the research and identify outliers.

\section{FINDINGS}

Key findings that emerged from the data involved the importance of story and counter-story sharing to fostering belonging, curiosity, and DML. Story sharing is a key component of the semi-structured conversation guide (Appendix A), including the allocation of time to share stories as a foundation of the relational micro-intervention. Sub-findings are: (a) the role of story sharing in building rapport and relationship, (b) the influence of taking time to share stories, and (c) the importance of structure.

\section{The Role of Story Sharing and Time in Building Rapport and Relationship}

One trend that emerged from the data was that students said they found meaningful connection and commonality with their partner through the sharing of stories and counter-stories. Connection and commonality are foundations of relationship building and can encourage sense of belonging and increase level of curiosity. This was true whether students approached the engagement with a wary attitude, excitement, or indifference. Three-fourths of the students interviewed said story and counter-story sharing not only helped them find connection with their other, it also led to greater respect and empathy and the building of a small-scale relationship. In addition to fostering belonging and curiosity, the act of story sharing, as structured into the conversation guide, can improve DML.

Sarah, who returned to college after having children, was paired with a Russian student who had moved to the U.S. as a teen. She said her paired partner "had a completely different background than I did, and yet we found more similarities than differences, and the differences really didn't seem to matter, you know?" When asked why their differences didn't matter, Sarah relayed a story that her partner, an immigrant to the U.S., shared with her. He works as an aide at a hospital, and Sarah described that in his work setting,

You really have to accept people the way they are. If someone comes in and you disagree with their religion or their politics or their lifestyle, it doesn't matter. You help them. And, it really bothers him when he hears some of the nurses judging patients... That was not a generosity that I was expecting. It's not what I usually expect from people.... It made me feel really good, like there are good people in the world. Yay! We had a lot of fun connecting over that and the importance of taking people where they are, and the value of every person.

Rochelle, a straight white student who chose two-year college over fouryear college because of finances, explained that story sharing helped her and her 
partner build connection and achieve a natural conversation. This led to Rochelle's partner feeling enough of a sense of belonging to share a personal story with her, which Rochelle said helped her connect more fully.

They opened up to me a little bit and told me things that I would never expect to find out about them.... I was like, I feel very privileged that you're sharing that with me, because I wouldn't expect you to open up to me that fast. But after that, I kind of felt more comfortable talking to the person.

In Rochelle's case, the effects of story sharing went beyond her microintervention, as revealed when she acknowledged that her partner's willingness to share his story led her to consider that maybe others she had othered based on differences might also be more similar to her than she thought, piquing her curiosity about people she considered different from her.

Omar, a mixed-race student of Muslim and Mormon parents, also recognized that he and his partner were different but expressed excitement about the conversation and his growing feelings of belonging and curiosity, based on the stories they shared with each other that revealed their similarities. In his words:

She grew up Christian, and now she's Christian, but she doesn't raise her kids Christian per se. She doesn't like force it on them... and, I was like the total opposite, because I had Islam and Mormon forced on me.... So, it was enlightening to me [that] she wasn't doing that, and she understood people have their own choices, and people make their own decisions, especially for her own kids. That was pretty cool.

Once Omar and his partner established rapport and connection through story and counter-story sharing, they began to feel accepted by each other, increasing sense of belonging. As they began to build their relationship, their curiosity about each other grew, and they sought and discovered more commonalities.

I found out she was a [CC] student, as well..., and she was just applying for a bunch of student loans, so we kind of connected on that, because she was one step ahead of me, because I'll be applying for student loans soon enough, and so that was kind of cool... I think we bonded most about college, just, you know, how expensive it is or how people expect someone to be able to afford housing and work and things like that.

This connection and relational foundation also helped foster DML, allowing Omar and his partner to discuss their differing political views with respect and discover further commonality and connection.

She had a lot of views that were similar to mine, which was surprising because she was 14 years older than me; she had kids; just farther along in life; and she was a Republican, but like we had all the same views. She - (whispers) she had a pot plant in her backyard, which I-honestly, I 
didn't even want to bring up marijuana to her, because I thought she was like-I don't know what she would've thought, because she knows I'm from California. And, she even told me that she profiled me when she saw me, saying that I looked like I smoked (laughter).

Kathy, a White student who defined herself as conservative, straight, and introverted, was paired with someone who, on paper, was very differentextroverted, progressive, Black, and bisexual. Kathy said she expected to be othered. Though Kathy and her partner recognized their differences, they bonded over the commonalities they discovered while sharing stories and counter-stories about how they were treated in their communities, increasing sense of belonging. In addition, this story sharing enabled Kathy to empathize with her partner, an important component of DML in engagement. As Kathy described:

In her class, the students around her yelled out, 'effing n-----. Shut up, n----.' And, the teacher didn't do anything to stop it. And, she said that people in her town tell her that she shouldn't exist because she's Black.... Obviously, that's unthinkable.... I have never even heard someone use that word besides maybe a Black person.... Other than that, I would never even think about having that word said in a derogatory way, let alone in a classroom with no-like they didn't get in trouble. There was no backlash to using the word.

Kathy explained that she related to this story, even though she admitted that she has never felt unsafe when challenged on her views. Given this, Kathy said she felt a kinship with her partner, because Kathy also felt politically othered as a conservative in a progressive community.

Once connection and rapport were established as a foundation for belonging, Kathy and her paired partner continued to build their relationship via their growing curiosity by discussing political issues, discovering agreement on issues such as gun control, gay marriage, and undocumented immigrants paying taxes. Kathy said they were both surprised, because the views on which they agreed are generally ascribed to one political party or another. As she explained,

I said, 'do you think that illegal immigrants should pay taxes?' [She said] 'Oh, yeah, they should.... and if they commit a crime, they shouldn't be here'... and I was like, 'you know if you said that here, you'd probably be considered a Republican, right?' She was like, 'oh, wow. I didn't think that.' Then she brought up the Second Amendment and creating restrictions and having a mental capacity test done. And I was like, 'yeah, that's completely reasonable. I think that would be a great thing'.

Kathy expressed that her experience sharing stories and counter-stories and exploring issues with someone who, on paper, was so different was, in her words, 
very valuable and made me take away a little bit of the weight that people held over me in terms of my beliefs and politics, because hearing what she had to say kind of made me feel like, why should anyone hate me.... I felt a lot of the same things as she did, because I'm very moderate in my leaning. I wouldn't even [say] I'm on the right side. I just think I lean right.... So, it definitely just made me take other people's opinions with more of a grain of salt.

Kristina - a progressive, mature woman paired with a young, conservative male military veteran - also discovered similarities amongst difference through story and counter-story sharing. These similarities helped her find empathy for her partner and made her more curious to explore his story. As she explained,

We had like similar situations with family and raising kids, and he was wanting to start a business, but he was in his practical job. So, we both could relate to that, you know, being in, like, well this is our fun thing that we want to do, and this is our jobbie-job that we have to do. And, so we both had that.

Later, when Kristina's partner shared his experiences in the military and that he "had a problem with Muslims," Kristina said the commonalities previously established via story sharing and rapport building helped her try to see his perspective, rather than judge him, as she might have if she had heard his comments in isolation.

I sympathized with him, saying, 'oh, yeah, it sounds like you were really scared.' Then, that made me think, okay, maybe people that think that we need to have a ban or something are coming from the idea of they're really scared.

This was a perspective Kristina had not considered before. Therefore, without agreeing or validating his need to other an entire group of people, she was able to acknowledge him and offer empathy, practicing DML skills.

In addition to acknowledging and offering empathy, Kristina was able to share a story to help moderate the significant ideological divide between her and her paired partner. "I told him the story of how my brother went there (to Iraq). He's done three tours.... He had translators, and he would befriend Muslims and thought they were awesome." Kristina's choice to share that her brother also served allowed her to find commonality and build connection with partner without needing to agree with him, the essence of DML in engagement.

\section{The Influence of Taking Time to Share Stories}

An important aspect of finding commonality across difference through story and counter-story sharing involves taking time to share and listen to stories and counter-stories, an important component of DML and the fostering of belonging and curiosity. 
Several students mentioned the construct of time, saying that the time they spent sharing stories and getting to know each other helped forge connection, establish rapport, and reveal commonality. This is illustrated by Tommy, who said, "time getting to know each other helped us more easily find common ground." Because they took time to share stories and get to know each other, Tommy discovered that he and a paired partner had sports in common. He plays football for the school, and his partner was a basketball player. In his words:

She played basketball at the school.... That was probably the best part, going sort of away from the questions for a second, we actually got a better understanding of each other, because we actually got to know each other.... So, when we actually got to the actual questions, we would feel more comfortable asking... and answering those questions with each other.

Time spent in the micro-intervention (30-60 minutes) sharing and listening to stories and counter-stories led many students to challenge their preconceived notions, thus fostering curiosity. Rochelle said differences between her and her partner became less important as the conversation continued, explaining:

Just being able to talk like we're regular people instead of having this super awkward stranger wall between us, I was really surprised at how easy it was to open up to this person, which was interesting. I expected it to be very like formatted, and the whole time to be looking at the sheet, and we did reference the sheet, but it wasn't the entire time, like, 'oh, what's next?' It was kind of after a while the ability to just have a continuous conversation.

Kristina attributed the time she and her other spent sharing stories to being able to treat each other with respect and empathy when differences did arise.

\section{The Importance of Structure}

Emerging from the data were findings related to the importance of imposing a structure, in this case a semi-structured guide, on a relational micro-intervention across difference. Bella, who said she had trouble making connections with people, articulated throughout her interview that she appreciated the semi-structured engagement across difference, because it provided an experience she could not cultivate on her own. Ben, a straight, mixed-race male who came to the $\mathrm{CC}$ directly from high school, said sticking to some sort of structure or guide helped him have a strong conversation with his partner. He explained, "I went through some of the questions - like what do you like to do in life? Why do you like to do it? I kind of tried to stick to non-political things, and that seemed to work." Tommy said they glanced at the guide to begin their conversation, but then they did not look at the guide for a while as they shared, connected, and built rapport. As he described,

The first 25 minutes of the conference... we were still getting to know each other. [Then], nobody had any more say. But, it wasn't an awkward silence. 
It was kind of a comfortable silence in the sense that that was the point where... we went right into it. Nothing changed.

Tommy reported that they did not stay on topic, which he thought was positive, and which was in line with the study's overall semi-structured design. In this off-topic time, Tommy said they discovered many connections, including college experience, sports, weather, and what they do in their free time. In his words:

It was really cool. I won't lie-we got a little off topic. We had actually a really good, probably 20-25-minute conversation... of us talking and comparing our areas, classes..., what do we do on weekends, how's the weather, like the seasons. ... We would kind of get on tangents and talking about lots of things.... That was really interesting to see how we all matched up in the same study but from a completely different subject.

Because they spent so much time getting to know each other, Tommy said the resulting conversation felt natural and familiar, an indication that everyone felt a sense of belonging in the digital space.

The common ground sort of found itself, in a sense. Everything we talked about [everyone] was so respectful and listening.... That created common ground.... We had common ground before we even started talking, because of the 20-minute period we had getting to know each other first.

In another instance of authentic connection during time away from the conversation guide, Maria, a mixed-race Filipino LGBTQ+ student, expressed that she got so caught up in the experience of making what she considered a new online friend that she either did not stop to think about differences or found the differences positive. In her words:

I forget that people have accents in America. So, I thought it was super cute. Just like, oh my gosh, she sounds so nice.... We just talked and talked about what we like and stuff. It felt like a speed date type thing - like just get in and get to know each other like really fast. It was just really nice.

Kathy and her paired partner started off on the defensive with each other, as is revealed in the below exchange. However, the semi-structured conversation guide helped them move from a defensive stance to connection across their differences, leading them both to feel a sense of belonging and become more curious about each other.

When we started talking, you could tell that she went into it pretty defensive, and I wasn't even going to say anything, because I'm not willing to push on those sorts of topics. [Researcher: Would you say that you might have been 
slightly defensive, too?] No, I'm not defensive at all when it's someone who actually listens (said slightly defensively).

Even though Kathy and her partner were guarded at the beginning, they did find common ground as they talked and shared using the semi-structured conversation guide. By the end of the conversation, Kathy revealed that she had learned from her partner.

One student, May, strayed from the conversation guide, instead "going down the list" of issues from a survey, rather than focusing on the relationship prompts from the guide. As May stated,

In the beginning, we were both sort of awkward. Like, how do we start this? What are we supposed to talk about? ... Finally, I was like, 'okay, I'm going to put up the questions that she gave us that we can like use to ask each other. So, we sort of ran through those, and it was like really awkward. We're just like, 'okay. Name. Age. This. That.' Then, after that, we brought up the social issues..., and ran through those. And, it was a pretty lackluster experience... I mean, I think it was hard to get a genuine conversation flowing, since we sort of felt like there were just these requirements we have to go through, like check the checklist....

Researcher: So, the conversation guide would have, like tell me a story about this or that. Did you do any of that?

May: No, I don't think so. I don't remember doing that.

While May's conversation did yield some interesting data, failing to follow the semi-structured conversation guide led May and her partner to struggle, indicating that fostering DML, belonging, and curiosity may require some guidance.

\section{DISCUSSION}

Findings reveal the influence of story and counter-story sharing on sense of belonging, level of curiosity, and DML of the students who were interviewed. The foundational action of sharing and listening to stories and counter-stories led to more rich or nuanced conversations and connections among students and their others, laying the foundation for the forging of small-scale relationships and the development of curiosity and a sense of belonging, critical aspects of DML and foundational to educational persistence, retention, and success. The parameters of time and structure also played a role.

Students who shared and listened to stories and counter-stories reported positive experiences in the micro-intervention, rapport and recognition, and connection and relationship with their other during, and sometimes following, the conversation. These findings are consistent with research on the power of narrative, including story and counter- story to empower students, create meaning, challenge myths, and help students share knowledge and connect across difference (Delgado, 1989), in particular when the story runs counter to the dominant narrative 
(Solórzano \& Yosso, 2002). Critical Race Theory (CRT) establishes the positionality of one story as counter-narrative to the multiple stories in a dominant, mainstream narrative, which have been told multiple times and repeated over time (Ladson-Billings \& Tate, 1995; Solórzano \& Yosso, 2002). In many cultures, story sharing is seen as knowledge sharing (Bernal \& Villalpando, 2002). In this framework, students who engage in a relational micro-intervention across difference engage in knowledge sharing as they share and listen to each other's stories, which can foster belonging and curiosity as students learn about each other.

Findings related to story and counter-story sharing are also consistent with DML in engagement (Park et al., 2014). Enabling students to move past stereotypes can help them connect with more nuanced and diverse information and others (Junco \& Cole-Avent, 2008), rather than remain in filter bubbles and echo chambers (Kahne \& Bowyer, 2016; Enter the Electome, 2016). Exposing students to diverse perspectives, as is done in a semi-structured micro-intervention across difference, is a key element of DML education (Kahne et al., 2012; Kim \& Yang, 2016; Mihailidis \& Thevenin, 2013), facilitating digital engagement (Enjolras et al., 2013; Gil de Zuniga, 2012; Kim et al., 2016), and enabling students to be more productive stewards of participatory democracy (Simsek \& Simsek, 2013). This finding is supported by the study's framework (Chavez et al., 2003), given the significance of moving from dualism to relativism on the ability to see others as fully formed people, rather than a collection of stereotypes.

Related is the construct of time taken to share and listen to stories. Though a micro-intervention is, by design, a small, short, one-time intervention, time played a significant role in students' experiences and feelings of connection with their paired partners. Students who spent time engaging in the initial relational section of the semi-structured conversation guide reported discovering commonality and connection. As mentioned above, the student who did not take the time at the beginning of the micro-intervention to share stories with her partner had a lackluster experience. The pivotal role of structure - specifically the relational semistructured engagement guide - in students' experiences with the micro-intervention was notable, including the richness and nuance of conversations across difference and mitigating students' perceptions of their others toward commonality, rapport, and connection-i.e. relationship. This is a potentially important finding, because it suggests that some level of instruction or guidance is necessary to teach students how to engage across difference, which aligns with existing research showing that engagement with diverse peers is a learned behavior (Hall et al., 2010) and that guidance is necessary to help students hone DML skills (Hargittai et al., 2010; Kahne \& Bowyer, 2016) and increase sense of belonging and level of curiosity.

Structure also emerged as a key finding influencing students' experiences engaging in the semi-structured micro-intervention across difference. Several examples emerged from students' interviews related to the influence of the semistructured design on their experience, including Kathy, who began on the defensive with her partner but found connection through and in spite of initial defensiveness, because she and her other followed the conversation guide, shared stories, built rapport, established trust, and found commonality across difference. This helped foster their feelings of belonging and curiosity toward each other. 
Another potentially significant finding related to the importance of structure is that several students brushed past differences to focus on commonality. Though students acknowledged difference, they tended to minimize it as less important than the similarities they discovered sharing stories as outlined in the guide, even though in many contexts, these differences are often seen as paramount and represent dividing lines in our socio-political landscape. This suggests that it is possible to guide students who are different to connection and foster belonging and curiosity through the use of a semi-structured design, providing hope that semi-structured, relational micro-interventions across difference could foster curiosity about others and increase sense of belonging, laying the groundwork for improved DML.

\section{Limitations and Recommendations for Further Study}

This research was exploratory in nature. It provided a compelling snapshot of how a semi-structured, relational micro-intervention across difference in a digital space can influence college students' sense of belonging, level of curiosity, and DML by establishing rapport, connection, recognition, and small-scale relationship in a digital space. Further research could illuminate and explore the impacts of such engagements.

A potential limitation is that the cohort utilized in this study included students from all academic years. Given potential implications for persistence and retention, coupled with research showing the importance of retaining students from their first to second semester, studying a cohort of first-year students may yield additional data on the effectiveness of this intervention. Also, conducting this study on a larger cohort and over a longer period of time could yield generalizable and longitudinal data on student attainment.

Another potential limitation is that others in this study were from a different college than the study participants. While this provided rich opportunities to match along multiple parameters of otherness, research among students on the same campus may yield interesting and potentially more important data on campus climate.

It is also important to continue assessing and refining what is meant by difference. Students in this study took surveys measuring policy differences, answering demographic questions, and completing scales on belonging, curiosity, and engagement. Though all data points were used to match students with an other across one or more parameters, the political and policy surveys may have played an outsized role. Researchers conducting future studies may wish to further refine this process.

Several students in this study experienced an issue with the digital interface that had the potential to impact their experience, from technical difficulties that delayed conversation or forced students to use the phone, to user error preventing students from effectively navigating the online engagement interface. Future studies can make the scheduling process smoother or conduct the microinterventions during class time. Though challenges and missteps did occur for some, the data indicate that students who experienced challenges and missteps generally still had meaningful engagements. 


\section{Conclusion}

At the core of this research is the proposition that engagement with one's other in a semi-structured, relational micro-intervention in a digital space has the potential to foster rapport, recognition, and connection across difference, leading to the building of small-scale relationships, and increasing sense of belonging and curiosity among college students. This in turn could positively impact campus climate and student attainment. It may also influence how students engage with their larger communities, an important aspect of DML. College students are citizens of a global and rapidly changing world who have the potential of impacting the direction of their communities and society. Given this, it is critical that community college leaders teach DML skills on how to engage and build relationships with those who are different (Hall et al., 2010; Hargittai et al., 2010; Kahne \& Bowyer, 2016). Of course, one intervention is not a silver bullet, and no one thing can solve these persistent and stubborn challenges. However, micro-interventions (Aguilar et al., 2014; Walton \& Cohen, 2007; Walton et al., 2015) can have large impacts. By focusing on all students, both marginalized and privileged, community college leaders can ensure that students from all backgrounds learn how to engage with each other.

Given the current U.S. political context - a nation divided (Enter the Electome, 2016; Suh, 2014) — and the resultant siloing and filter bubbles (Hargittai et al., 2010; McGrew et al., 2018; Enter the Electome, 2016), strategies that create bridges to connect and foster relationships among us are critical (DiMaggio \& Garip, 2012; Hurtado \& Ponjuan, 2005; Locks et al., 2008). Because of the increased media attention to ideological and policy divides, as well as the vilifying and othering of historically marginalized groups, including our undocumented neighbors, Muslims, Deferred Action for Childhood Arrival (DACA) recipients, the Black community, and women as they work to have their voices heard through the \#MeToo movement, the political will may now exist to address and heal these divides on campus before they become normalized in our societal structure and go on to reverberate in communities across the U.S.

\section{REFERENCES}

Aguilar, L., Walton, G., \& Weiman, C. (2014). Psychological insights for improved physics teaching. Physics Today, 67(5), 43-49.

Ayala, G. X., Elder, J. P., Campbell, N. R., Arredondo, E., Baquero, B., Crespo, N. C., \& Slymen, D. J. (2010). Longitudinal intervention effects on parenting of the Aventuras para Niños study. American Journal of Preventive Medicine, 38(2), 154-162.

Bennett, M. J. (1993). Towards a developmental model of intercultural sensitivity. In M. Paige (Ed.), Education for the intercultural experience. Yarmouth, MA: Intercultural Press.

Bernal, D. D., \& Villalpando, O. (2002). An apartheid of knowledge in academia: The struggle over the "legitimate" knowledge of faculty of color. Equity and Excellence in Education, 35(2), 165-180. 
Betancourt, J. R., Green, A. R., \& Carillo, J. E. (2003). What is cultural sensitivity and cultural competency? Public Health Reports, (118), 293-302.

Bonet, G., \& Walters, B. R. (2016). High impact practices: Student engagement and retention. College Student Journal, 50(2), 224-235.

Bruhn, J. G. (2004). Sociology of community connections. Place of publication not identified: Springer.

Buote, V. M., Pancer, S. M., Pratt, M. W., Adams, G., Birnie-Lefcovitch, S., Polivy, J., \& Wintre, M. G. (2007). The importance of friends: Friendship and adjustment among 1st-year university students. Journal of Adolescent Research, 22(6), 665-689.

California Community Colleges Key Facts (2016). Retrieved from http://californiacommunitycolleges.cccco.edu/PolicyInAction/KeyFacts.as px

Caminha, C., Furtado, V., Pinheiro, V., \& Silva, C. (2016). Micro-interventions in urban transportation from pattern discovery on the flow of passengers and on the bus network. 2016 IEEE International Smart Cities Conference (ISC2), 1-6.

Charmaz, K. (2002). Qualitative interviewing and grounded theory analysis. In J. F. Gubrium \& J. A. Holstein (Eds.), Handbook of interview research: Context \& method (pp. 675-94). Thousand Oaks, CA: Sage.

Chavez, A. F., Guido-DiBrito, F., \& Mallory, S. L. (2003). Learning to value the "other": A framework of individual diversity development. Journal of College Student Development, 44(4), 453-469.

Creswell, J. W. (2014). Research design: Qualitative, quantitative, and mixed methods approaches. Los Angeles: SAGE.

Delgado, R. (1989). Storytelling for oppositionists and others: A plea for narrative. Michigan Law Review, 87(8), 2411-2441.

DiMaggio, P., \& Garip, F. (2012). Network effects and social inequality. Annual Review of Sociology, 38, 93-118.

Enjolras, B., Steen-Johnsen, K., \& Wollebaek, D. (2013). Social media and mobilization to offline demonstrations: Transcending participatory divides. New Media \& Society, 15(6), 890-908.

Enter the Electome. (2016). MIT. Retrieved December 13, 2016, from http://www.electome.org/

Fagioli, L. P., Rios-Aguilar, C., \& Deil-Amen, R. (2015). Changing the context of student engagement: Using Facebook to increase community college student persistence and success. Teachers College Record, 2015(117), 142.

Freire, P., \& Macedo, D. P. (1987). Literacy: Reading the word and the world. South Hadley, MA: Bergin \& Garvey.

Gil de Zuniga, H. (2012). Social media use for news and individuals' social capital, civic engagement and political participation. Journal of ComputerMediated Communication, 17(3), 319-336.

Hall, W. D., Cabrera, A. F., \& Milem, J. F. (2010). A Tale of two groups: Differences between minority students and non-minority students in their 
predispositions to and engagement with diverse peers at a predominantly White institution. Research in Higher Education, 52(4), 420-439.

Hammer, M. (1983). "Core" and "extended" social networks in relation to health and illness. Social Science and Medicine, 17(7), 405-411.

Hargittai, E., Fullerton, L., Menchen-Trevino, E., \& Thomas, K. Y. (2010). Trust online: Young adults' evaluation of web content. International Journal of Communication, 4(2010), 468-494.

Hausmann, L. R., Schofield, J. W., \& Woods, R. L. (2007). Sense of belonging as a predictor of intentions to persist among African American and White first-year college students. Research in Higher Education, 48(7), 803-839.

Hulme, E., Green, D. T., \& Ladd, K. S. (2013). Fostering student engagement by cultivating curiosity. New Directions for Student Services, 2013(143), 5364.

Hurtado, S., \& Ponjuan, L. (2005). Latino educational outcomes and the campus climate. Journal of Hispanic Higher Education, 4(3), 235-251.

Itzhaky, H., \& Dekel, R. (2005). Helping victims of terrorism: What makes social work effective? Social Work, 50(4), 335-343.

Johnson, J., Bottorff, J., Browne, A., Grewal, S., Hilton, B., \& Clarke, H. (2004). Othering and being othered in the context of health care services. Health Communication, 16(2) 253-271.

Junco, R., \& Cole-Avent, G. A. (2008). An introduction to technologies commonly used by college students. New Directions for Student Services, 2008(124), 3-17.

Kahne, J., \& Bowyer, B. (2016). Educating for democracy in a partisan age. American Educational Research Journal, 54(1), 3-34.

Kahne, J., Lee, N., \& Feezell, J. T. (2012). Digital media literacy education and online civic and political participation. International Journal of Communication, 6, 1-24.

Kim, Y., Wang, Y., \& Oh, J. (2016). Digital media use and social engagement: How social media and smartphone use influence social activities of college students. Cyberpsychology, Behavior, \& Social Networking, 19(4), 264-269.

Kim, E., \& Yang, S. (2016). Internet literacy and digital natives' civic engagement: Internet skill literacy or Internet information literacy? Journal of Youth Studies, 19(4), 438-456.

Ladson-Billings, G., \& Tate, W. F. (1995). Toward a critical theory of education. Teachers College Record, 97(1), 47-68.

Lieberman, M. D. (2013). Social: Why our brains are wired to connect. Oxford, UK: Oxford University Press.

Locks, A. M., Hurtado, S., Bowman, N. A., \& Oseguera, L. (2008). Extending notions of campus climate and diversity to students' transition to college. Review of Higher Education, 31(3), 257-285.

Luthans, B. C., Luthans, K. W., \& Avey, J. B. (2014). Building the leaders of tomorrow. Journal of Leadership \& Organizational Studies, 21(2), 191199. 
Martens, H., \& Hobbs, R. (2015). How media literacy supports civic engagement in a digital age. Atlantic Journal of Communication, 23(2), 120-137.

Masika, R., \& Jones, J. (2015). Building student belonging and engagement: Insights into higher education students' experiences of participating and learning together. Teaching in Higher Education, 21(2), 138-150.

Mather, P. C., \& Hulme, E. (2013). Positive psychology and appreciative inquiry in higher education. San Francisco: Jossey-Bass.

McGrew, S., Breakstone, J., Ortega, T., Smith, M., \& Wineburg, S. (2018). Can students evaluate online sources? Learning from assessments of civic online reasoning. Theory \& Research in Social Education, 46(2), 165193.

Mendoza-Denton, R., \& Page-Gould, E. (2008). Can cross-group friendships influence minority students' well-being at historically White universities? Psychological Science, 19, 933-939.

Mihailidis P., \& Thevenin, B. (2013). Media literacy as a core competency for engaged citizenship in participatory democracy. American Behavioral Scientist, 57(11) 1611-1622.

Miles, M. B., Huberman, A. M., \& Saldaña, J. (2014). Qualitative data analysis: A methods sourcebook (3rd ed.). Thousand Oaks, CA: Sage.

Moeller S. (2010). A day without media. International Center for Media \& the Public Agenda. Retrieved May 18, 2016, from http://withoutmedia.wordpress.com

Nelson, D., \& Cooper, C. L. (Eds.) (2007). Positive organizational behavior: Accentuating the positive at work. Thousand Oaks, CA: Sage.

O'Keeffe, P. (2013). A sense of belonging: Improving student retention. College Student Journal, 47(4), 605-613.

O’Neal, C. W., Mancini, J. A., \& Degraff, A. (2016). Contextualizing the psychosocial well-being of military members and their partners: The importance of community and relationship provisions. American Journal of Community Psychology, 58(3-4), 477-487.

Park, S., Kim, E., \& Na, E. (2014). Online activities, digital media literacy, and networked individualism of Korean youth. Youth \& Society, 47(6), 829849.

Pierce, C. I. (1970). Offensive mechanisms. In F. Barbour (Ed.), The Black seventies (pp. 265-282). Boston: Porter Sargent.

Roberts, J., Yaya, L., \& Manolis, C. (2014). The invisible addiction: Cell-phone activities and addiction among male and female college students. Journal of Behavioral Addictions, 3(4), 254-265.

Shook, N., \& Clay, R. (2012). Interracial roommate relationships: A mechanism for promoting sense of belonging at university and academic performance. Journal of Experimental Social Psychology, 48(5), 1168-1172.

Silvia, P. J. (2008). Interest: The curious emotion. Current Directions in Psychological Science, 17(1), 57-60.

Simsek, E., \& Simsek, A. (2013). New literacies for digital citizenship. Contemporary Educational Technology, 4(2), 126-137. 
Smith, D., \& Schonfeld, N. (2000). The benefits of diversity: What the research tells us. About Campus, 5(5), 16-23.

Smith, P. K., Mahdavi, J., Carvalho, M., Fisher, S., Russell, S., \& Tippett, N. (2008). Cyberbullying: Its nature and impact in secondary school pupils. Journal of Child Psychology and Psychiatry, 49(4), 376-385.

Smyth, J. M., \& Heron, K. E. (2016). Is providing mobile interventions "just-intime" helpful? An experimental proof of concept study of just-in-time intervention for stress management. 2016 IEEE Wireless Health, (WH), 89-95.

Solórzano, D. G., \& Yosso, T. J. (2002). Critical race methodology: Counterstorytelling as an analytical framework for educational research. Qualitative Inquiry, 8(1), 23-44.

Strauss, A., \& Corbin, J. (1998). Basics of qualitative research: Techniques and procedures for developing grounded theory ( $2 \mathrm{nd}$ ed.). Thousand Oaks, CA: Sage.

Suh, M. (2014). Political polarization in the American public. Pew Research Center. Retrieved February 10, 2018, from http://www.peoplepress.org/2014/06/12/political-polarization-in-the-american-public/

Walton, G. M., \& Cohen, G. L. (2011). A brief social-belonging intervention improves academic and health outcomes of minority students. Science, 331(6023), 1447-1451.

Walton, G. M., Logel, C., Peach, J. M., Spencer, S. J., \& Zanna, M. P. (2015). Two brief interventions to mitigate a "chilly climate" and transform women's experience, relationships, and achievement in engineering. Journal of Educational Psychology, 107(2), 468-85.

Young, B. (1990). Not there yet: Women in educational administration. In Y. L. Jack Lam (Ed.), The Canadian public school system: Issues and prospects (pp. 85-102). Calgary: Detselig. 


\section{APPENDIX A: Conversation Guide}

Civity interactions are both intentional and focused on authentic human connection - the head and the heart working together. You are offering authentic respect and understanding in the hope that your authenticity will be reciprocated.

Offering authenticity to another person who you don't know that well can be a little risky - you might feel a little uncomfortable - that's natural!

\section{1) Begin the Conversation:}

- Exchange greetings

- Give some of your background

- Invite the other person to introduce themselves

- Go deeper - Explain how you care about your community, and tell a short personal story about where that comes from.

- This may feel risky as you are offering up a side of yourself that in most situations remains hidden.

- Invite the other person to reciprocate, to explain where their civic passion comes from.

- Remember to truly listen to them.

- Thank them for sharing their story; it's a gift to you!

\section{2) Deepen the Conversation:}

- Explain that you'd like to explore/understand; articulate the difference between the two of you, and, if it does, why it makes you somewhat uncomfortable.

- Ask/invite the other person to tell you one of their stories about that difference, or another.

- Listen to the other person's story, being intentional about providing space for them to tell their story honestly and genuinely. Also be aware of your own story, through which you are listening.

- If it makes sense, share a story of your own that focuses on the difference.

- Thank them for sharing their story!

\section{3) After the Conversation:}

- Don't worry if the other person did most of the talking - that means you successfully created the space for that person to be heard!

- Reflect on what happened; think about bringing a Civity mindset to other conversations. 